2. Reid MC, Lachs MS, Feinstein AR. Use of methodological standards in diagnostic test research. JAMA 1995;274:645-51.

\section{Injection anthrax causing compartment syndrome and necrotising fasciitis}

A 28-year-old woman was diagnosed with injection anthrax infection causing compartment syndrome and necrotising fasciitis of her arm. She was treated successfully with intravenous benzylpenicillin, clindamycin, ciprofloxacin and metronidazole. While in hospital she underwent two fasciotomies and six debridements of necrotic tissue over a 3-week period. Subsequent skin grafting was successful.

\section{CASE REPORT}

A 28-year-old female intravenous drug user presented with a 2-day history of increasing pain and swelling in her right arm, extending to her right shoulder. She had last injected heroin into her right antecubital fossa 5 days previously.

On admission she was feverish at $38^{\circ} \mathrm{C}$ and tachycardic. There was massive swelling of the arm, extending from her fingers to her shoulder, but no overt erythema. Initial laboratory findings revealed total white cell count of $15.5 \times 10^{9} / 1$, with neutrophilia and C-reactive protein of 38 . She was diagnosed with compartment syndrome and was taken to theatre the same day for multicompartment fasciotomy. On inspection, all tissue looked viable and no abscesses were identified. Swabs taken at surgery did not yield any growth on culture.

At this stage, this was considered to be a possible case of anthrax as the patient was an intravenous drug user with a clinical syndrome compatible with anthrax. The patient was given intravenous benzylpenicillin $2.4 \mathrm{~g}$ four times a day, clindamycin $1.2 \mathrm{~g}$ four times a day, ciprofloxacin $400 \mathrm{mg}$ twice a day, and metronidazole $500 \mathrm{mg}$ three times a day. Blood cultures were processed locally, while blood samples for anthrax PCR, toxin levels and serology were sent to the Special Pathogens Reference Unit, Porton Down, Salisbury, UK. Results for PCR on blood were negative, while results for toxin and antibody to protective antigen were equivocal.

Following surgery, the patient developed fever, tachycardia, hypotension and bleeding from her fasciotomy site. She returned to theatre 2 days postoperatively for a re-exploration of the wound. Necrotic areas of skin were identified in the antecubital fossa and upper arm. Fasciotomies were extended proximally in the upper arm, and two tissue biopsies were sent to the pathology department. A tissue sample was also sent to the microbiology department and this was forwarded directly to the Special Pathogens Reference Unit for Bacillus anthracis PCR.

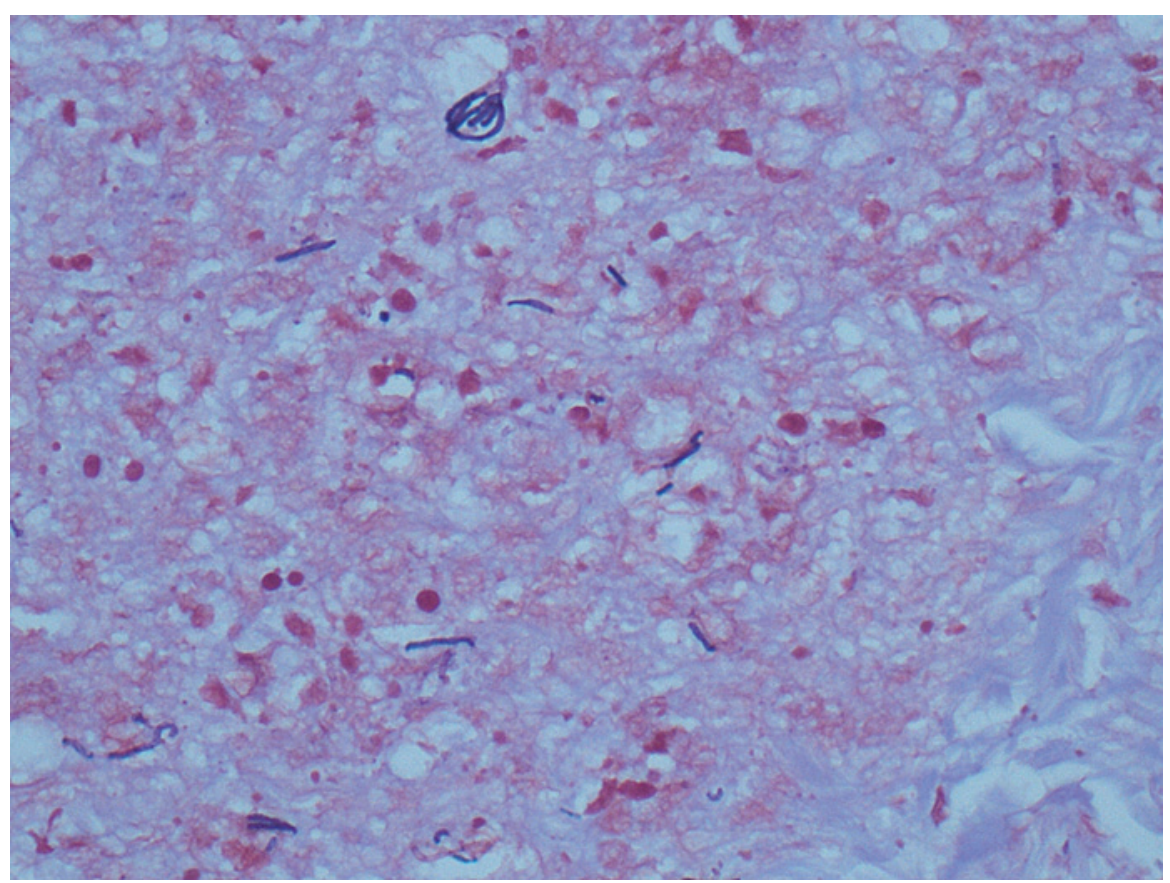

Figure 1 Gram-positive bacilli on histopathology.

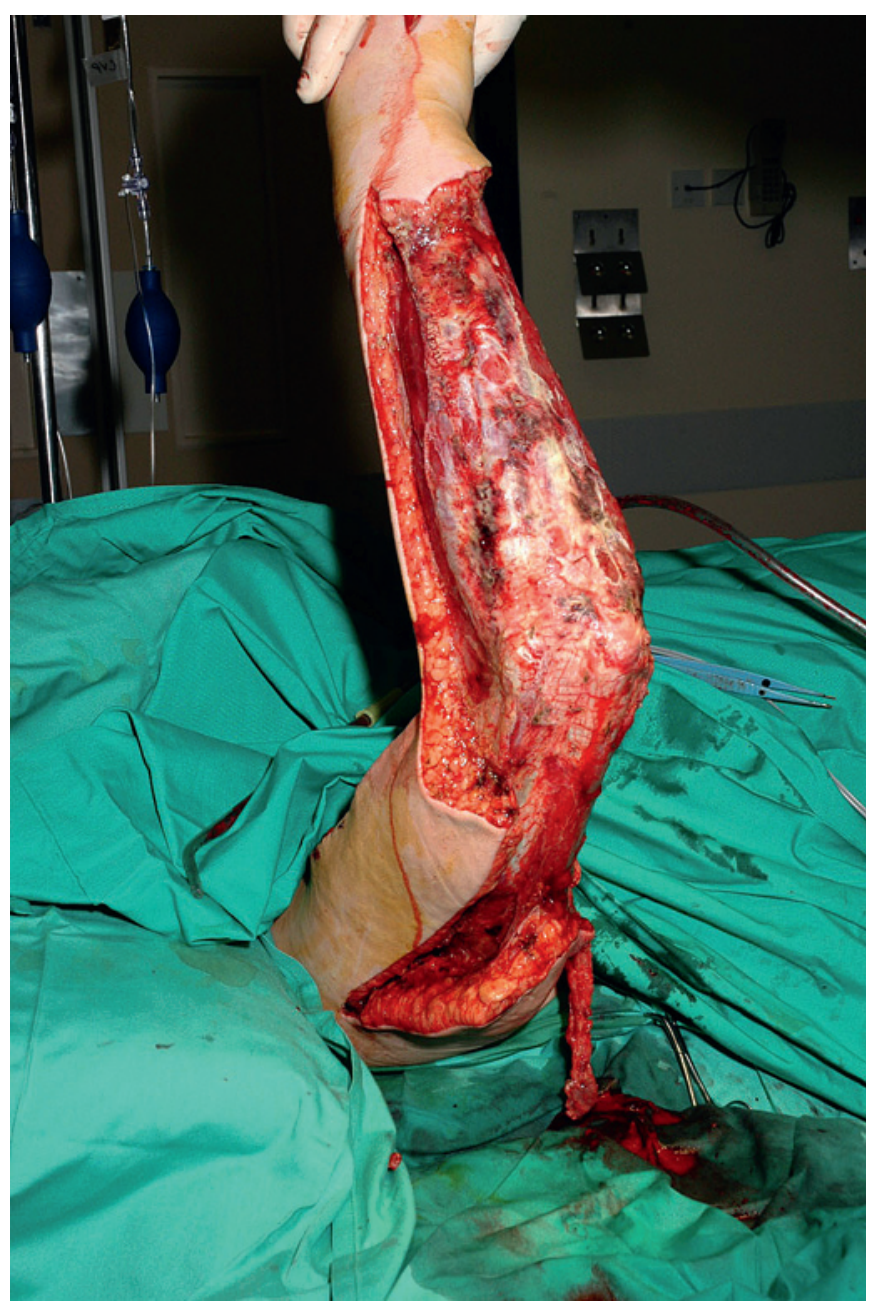

Figure 2 Arm after debridement of necrotic skin and fascia. 
Nine days after the patient was admitted, the diagnosis was confirmed with Grampositive bacilli on histopathology, (figure 1) and a positive PCR on tissue for $B$ anthracis at the Special Pathogens Reference Unit. We considered giving anthrax immune globulin, but it was not thought to be worthwhile because, at this late stage, toxin would have already bound to tissues. Over the next 2 weeks the patient returned to theatre six times for further debridement of necrotic skin and fascia (figure 2). Her clotting screen became deranged and she had further complications with bleeding and two intensive care unit admissions. In total, 37 units of blood were transfused while the patient was in hospital.

Twenty days after admission the patient underwent a split skin graft repair to her arm. She made good progress after this and intravenous antibiotics were stopped after 4 weeks. The patient was discharged 30 days after admission. Due to the theoretical risk of anthrax recurrence from spore formation, the patient received a further supply of oral ciprofloxacin in order to complete a 60-day course in total. On review of the wound after discharge from hospital the arm had healed well.

\section{DISCUSSION}

There has been an outbreak of anthrax among heroin users in the UK since December 2009. The first cases were identified in NHS Greater Glasgow and Clyde. So far, there have been 47 cases identified in Scotland, with 13 deaths. ${ }^{1}$ Contamination of heroin, or a cutting agent, is thought to be the most likely source of infection, but investigations are ongoing.

Prior to the present outbreak, there had only been one reported case of anthrax in an injecting drug user. It was described in Norway in 2000 when a man died from systemic anthrax after using a contaminated heroin skin-popper. ${ }^{2}$ As a result of this case the term 'injectional anthrax' was proposed. The most common presentation of anthrax

\section{Take-home messages}

- Injection anthrax infection can present with necrotising fasciitis.

- Blood should be sent for culture, Bacillus anthracis PCR, toxin and antibody testing. Gram stain, culture and PCR should be carried out on debrided tissue.

- A combination of antibiotics and multiple surgical debridements is needed to treat this life-threatening infection.

during the current outbreak has been an injection-related soft tissue infection such as cellulitis, abscess or necrotising fasciitis, with symptoms starting within 1-7 days after using contaminated heroin. ${ }^{3}$ Oedema is characteristically marked, as in our case.

If anthrax is strongly suspected, current guidance recommends that blood samples are taken for culture, PCR, toxin and antibody testing. Tissue or material from abscesses or lesions should be obtained for stain and culture. ${ }^{4}$ Diagnosis was delayed in our case because of a number of factors. First, blood cultures were obtained only after the patient was commenced on antibiotics. Second, only swabs (rather than tissue) were sent from theatre at the time of the first fasciotomy. Third, there was difficulty interpreting the significance of the results, as $B$ anthracis PCR on blood was negative, while toxin and antibody to protective antigen were equivocal. The diagnosis was finally confirmed 9 days after the patient was admitted when Gram-positive rods were identified on histology. The presence of $B$ anthracis DNA was determined by PCR on tissue, detecting three gene targets: lef (lethal factor gene, on plasmid pX01), capA (capsule gene, on plasmid pX02) and $B a g C$ (genomic).
Our patient received antibiotics active against $B$ anthracis from an early stage, but this case highlights the importance of multiple surgical debridements in treating this life-threatening infection.

Benjamin J Parcell, ${ }^{1}$ Andrew D Wilmshurst, ${ }^{2}$ Anthony J France, ${ }^{3}$ Luisa Motta, ${ }^{4}$ Tim Brooks, ${ }^{5}$ William J Olver ${ }^{1}$

${ }^{1}$ Department of Medical Microbiology, Ninewells Hospital and Medical School, Dundee, Scotland, UK; ${ }^{2}$ Department of Plastic Surgery, Ninewells Hospital and Medical School, Dundee, Scotland, UK; ${ }^{3}$ Infection Unit, Ninewells Hospital and Medical School, Dundee, Scotland, UK; ${ }^{4}$ Department of Pathology, Ninewells Hospital and Medical School, Dundee, Scotland, UK; ${ }^{5}$ Health Protection Agency Centre for Emergency Preparedness and Response, Novel and Dangerous Pathogens, Porton Down, Salisbury, UK

Correspondence to Dr Benjamin J Parcell, Medical Microbiology, Ninewells Hospital and Medical School, Dundee, Tayside DD1 9SY, Scotland, UK; b.parcell@nhs.net

\section{Competing interests None.}

Patient consent Obtained.

Provenance and peer review Not commissioned; externally peer reviewed.

Published Online First 20 November 2010

J Clin Pathol 2011;64:95-96.

doi:10.1136/jcp.2010.082586

\section{REFERENCES}

1. Health Protection Scotland. Anthrax Outbreak Information. http://www.hps.scot.nhs.uk/anthrax/ index.aspx (accessed 17 Jul 2010).

2. Ringertz SH, Hoiby EA, Jensenius $\mathbf{M}$, et al. Injectional anthrax in a heroin skin-popper. Lancet 2000;356:1574-5.

3. Health Protection Scotland. Anthrax in Drug Users Case Definitions Version 5.0. 2010. http://www.hps. scot.nhs.uk/anthrax/documents/case-definitionanthrax-outbreak-v5.pdf (accessed 18 Jun 2010).

4. Health Protection Agency. Clinical Algorithm: Clinical Evaluation and Management of Drug Users with Possible Anthrax. 2010. http://www.hpa.org.uk/web/ HPAwebFile/HPAweb C/1259152399460 laccessed 18 Jun 2010). 